УДК 664

05.00.00 Технические науки

ФОРМИРОВАНИЕ БАЗОВЫХ ОСНОВ УТИЛИЗАЦИИ ТЕХНИКИ НА РАЗЛИЧНЫХ ЭТАПАХ ЕЁ ЖИЗНЕННОГО ЦИКЛА

Еремеев Николай Сергеевич доктор техн. наук

ОАО «Центральный научно-исследовательский и проектно - конструкторский институт механизациии и энергетики лесной промыпленности» (ЦНИИМЭ), Россия

Email:tsniime@tsniime.ru

Игнатов Владимир Ильич канд. техн. наук

Федеральное государственное бюджетное научное учреждение «Федеральный научный агроинженерный центр ВИМ»,(ФГБНУ ФНАЦ ВИМ), Россия

E-mail: ignatoww@inbox.ru

Макуев Валентин Анатольевич

доктор технических наук

E-mail:makuev@mgul.ac.ru

Сиротов Александр Владиславович

доктор технических наук

МФ МГТУ им. Н.Э. Баумана, Москва, Россия

E-mail: Sirotov@mgul.ac.ru

В настоящее время в России проблема утилизации самоходных машин не решена. Это связано с тем, что в стране не выстроена четкая система взаимоотношений и взаимодействия между разработчиками, изготовителями и потребителями машиностроительной продукции. В работе проанализирован отечественный и зарубежный опыт по решению этой проблемы, дана краткая информация о разработке отечественной системы утилизации сельскохозяйственной техники

Ключевые слова: СИСТЕМА УТИЛИЗАЦИИ ТЕХНИКИ, РЕСУРСОСБЕРЕЖЕНИЕ, ЭКОЛОГИЯ, ЖИЗНЕННЫЙ ЦИКЛ ПРОДУКЦИИ

Doi: 10.21515/1990-4665-132-015
UDC 664

Engineering

\section{FORMATION OF BASICS FOR EQUIPMENT UTILIZATION ON VARIOUS LEVELS OF ITS LIFE CYCLE}

Eremeev Nikolay Sergeyevich

Doctor of engineering Sciences

Central research institute of mechanization and energetics of forest industry, (TSNIIME), Russia

Email:tsniime@tsniime.ru

Ignatov Vladimir Ilyich

Candidate of engineering sciences

Federal State Budgetary Scientific Institution «Federal Scientific Agroengineering Center VIM» (FSACVIM),

Russia

E-mail: ignatoww@inbox.ru

Makuev Valentin Anatolyevich

Doctor of engineering Sciences,

E-mail: makuev@mgul.ac.ru

Sirotov Aleksander Vladislavovich

Doctor of engineering Sciences

Mytischy Branch of Bauman Moscow State Technical

University

E-mail: Sirotov@mgul.ac.ru

Nowadays, in Russia the problem of utilization of selfpropelled vehicles has not been solved yet. This problem remains because in Russia there is no accurate system of cooperation between developers, producers and customers of mechanical products. The article analyses Russian and foreign experience in solving this issue, gives brief information about working out Russian system of agricultural machines utilization

Keywords: SYSTEM OF EQUIPMENT UTILIZATION, COST-EFFECTIVE USE OF RECOURSES, ECOLOGY, PRODUCT LIFE CYCLE

Научно-техническая революция (НТР) привела к трансформации индустриального общества в постиндустриальное. Взаимодействие науки и производства выявило новые потребности социума, а возможность их реализации привела к взрывному увеличению производства различных видов 
продукции. Объёмы мирового производства продукции машиностроения в течение XX-го века увеличились в 100 раз, в США - в 300 раз, а в Японии он вырос более чем в 500 раз [1]. За это время (100 лет) из недр планеты извлечено полезных ископаемых больше, чем за всю историю человечества.

Рост потребностей социума и технический прогресс привели к значительному росту производства и потребления производимой продукции (рисунок 1), и тренд этого процесса до настоящего времени положительный.

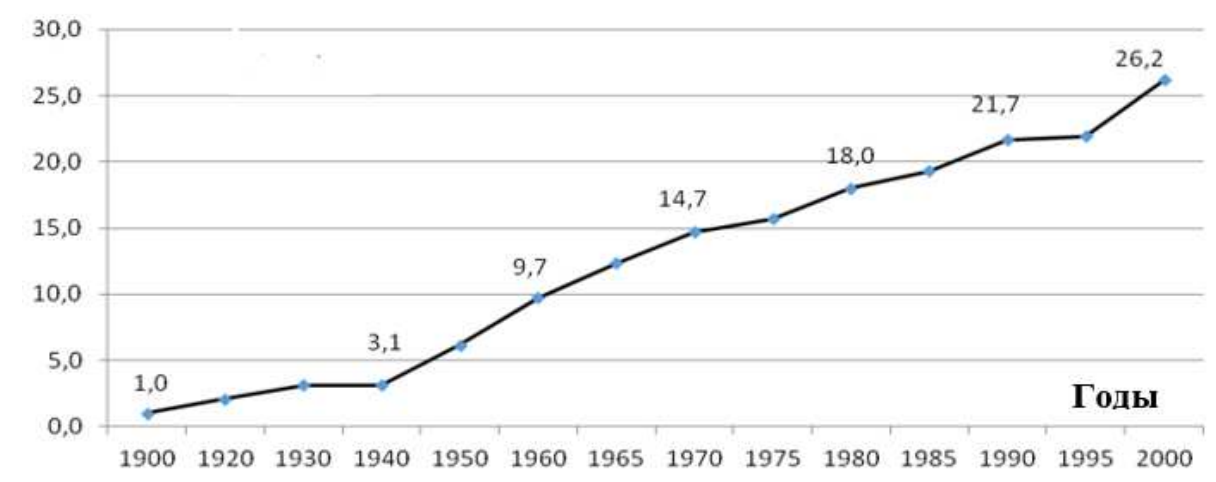

Рисунок 1 - Мировые темпы роста продукции машиностроения на душу населения в период с 1900 до 2000 г.

Этот процесс происходит при стабильном увеличении населения планеты [4] в течении прошлого и текущего столетий (рисунок 2).

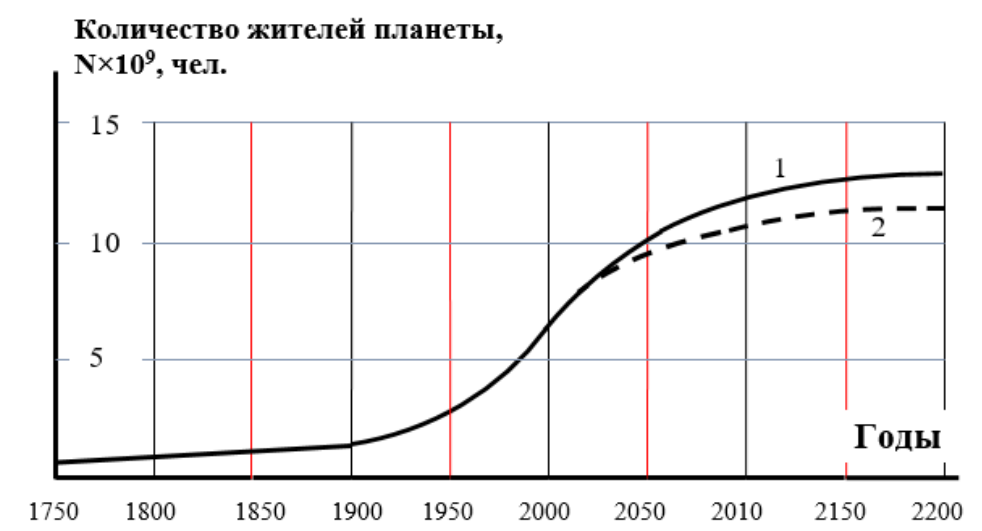

Рисунок 2 - Рост населения мира с 1750 по 2200 г.: 1 - прогноз ООН;

2 - прогноз С.П. Капицы

Уже в начале XX-го века технически развитые страны столкнулись с двумя негативными проблемами, связанными с НТР. Первая связана с увеличением объёмов производства и потребления продукции различных ви- 
дов. Рост населения, выявление новых потребностей социума способствуют расширению производство продукции различных видов и требуют увеличения объёмов добычи невосполнимых полезных ископаемых, что приводит к снижению их потенциальных запасов.

Особенно материалоёмкими являются транспортные средства (колёсная, самоходная, военная техника, железнодорожный и водный транспорт и пр. виды техники), на производство которых расходуется львиная доля получаемого сырья. Номенклатура материалов, которые используются при изготовлении этой продукции, включает в себя не только металлы, но и десятки других компонентов (пластмассы, резина, стекло и пр.), для производства которых требуются различное исходное сырьё, получаемое с использованием природных ресурсов. Например, для производства одной тонны чугуна необходимо около 3 тонн железной руды, 1,1 тонны кокса, 20 тонн воды, плюс различное количество сопутствующих материалов. Если учесть, что в настоящее время ежегодное производство чугуна в мире составляет более миллиарда тонн, то можно подсчитать, какие объёмы природных ресурсов извлекается из недр Земли только для получения только одного этого компонента техники. Металлофонд чёрного металла в РФ, входящего в составе изделий, которые имеют различный срок службы, оценивается на уровне 1,5 млрд. тонн,

Второй проблемой (важность которой была долгое время недооценена международным сообществом, и только в последние годы поставлена на государственный контроль в большинстве стран) является рост объёмов образования отходов производства и потребления.

Под отходами производства и потребления (далее отходы) в соответствии с законом [3, ст. 1] понимаются «вещества или предметы, которые образованы в процессе производства, выполнения работ, оказания услуг или в процессе потребления».

Под отходы потребления в соответствии с законом [4, ст. 2] понимаются «все образуюшиеся в результате потребления и (или) эксплуатащии готовой продукции виды отходов, включая твердые бытовые отходы, медичинские и биологические отходы, упаковочныле отходы, а также отходы, образующиеся при функиионировании культурно-бытовых, учебных учреждений, организаций и предприятий торговли и обще- 
ственного питания и других предприятий и организаций общественного назначения; остатки веществ, материалов, предметов, изделий, частично или полностью утратившие свои первоначальные потребительские свойства в результате физического или морального износа в процессах потребления и (или) эксплуатащии, а также получившие несовместимые с их дальнейшим использованием повреждения в результате нештатных ситуаицй».

Отходы образуются на всех стадиях жизненного цикла продукции (ЖЦП), в том числе при производстве и использовании техники различных видов (рисунок 3). При этом следует учесть, что даже самые совершенные (на момент их изготовления) модели техники относительно быстро морально и физически стареют, и становятся непригодными для использования по назначению и переходят в категорию отходов, но отходов материалоёмких и экологоопасных. Для сохранения и повторного использования имеющихся, в выведенной из эксплуатации техники (ВЭТ) компонентов требуется разработка и использование специальных технологий утилизации, учитывающих соответствующие требования ресурсосбережения и экологии [5], принципов организации и достаточно сложной системы утилизации (рециклинга).

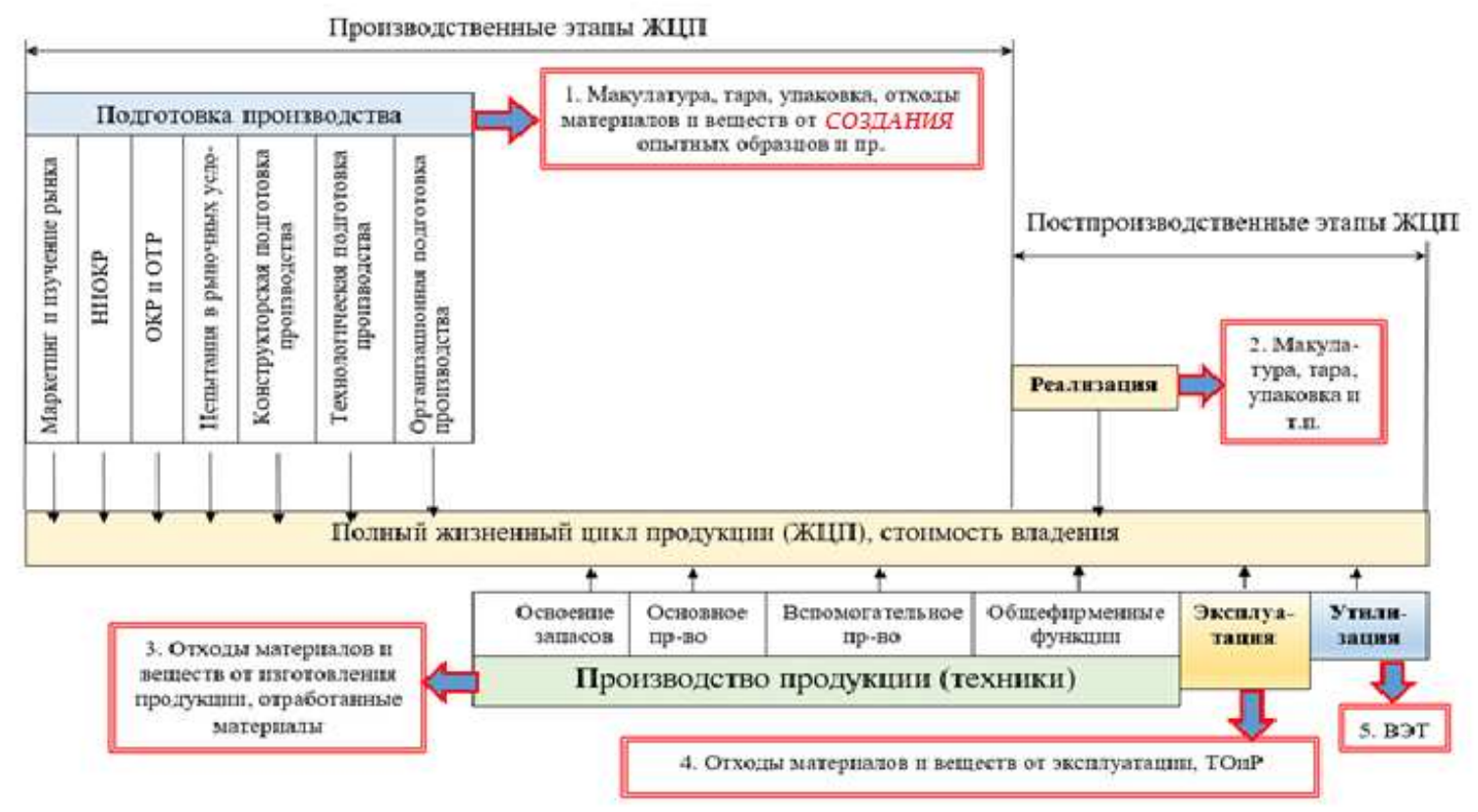

Рисунок 3 - Организационно-экономическая модель образования отходов на различных этапах производства и потребления продукции 
Всё это говорит о том, в настоящее время проблема, связанная с утилизацией отходов, превратилась в общемировую, и носит экономикополитический характер. С.П. Капица признаёт, что в истории человечества уже имелись локальные случаи исчерпания ресурсов и дефицита территории, которые заканчивались в лучшем случае мирным переселением, но чаще - войнами [2].

В технически развитых странах более 20 лет действуют законы о рециклинге, регламентирующие процессы обращения с отходами и обеспечивающие возврат в производство до 95\% компонентов, входящих в состав этих отходов. В основу этих законов положен принцип «загрязнитель платит», т.е. ответственность производителя за утилизацию продукции после окончания срока её службы и за соблюдение норм утилизации. В соответствии с этими нормативами, производители автомобилей должны разрабатывать и использовать технологи, обеспечивающие возврат до 95\% от массы ВЭТ.

В настоящее время, лидером в области утилизации отходов в целом (и отходов от ВЭТ в том числе) считается Германия. Принятый в этой стране 07.10.1996 закон «Об экономическом рециклинге Германии» [6] считается эталоном, который многими экспертами признан образцом в вопросах организации рециклинга техники (авторециклинга). Аналогичные законы приняты более чем в 50 странах мира. В странах-лидерах создана отрасль рециклинга техники, эффективность которой соизмерима с производством этой техники. В России решение проблемы обращения с отходами находится пока на стадии «эскизного проекта». Несмотря на то, что 24.06.1998 г. в России также был введён в действие закон «Об отходах производства и потребления» [3] и к настоящему моменту претерпел более 30 редакций (что говорит о его несовершенстве), проблема остаётся сложной. Сложность ситуации с утилизацией отходов говорить и то, что 2017 г. объявлен в России годом экологии. Тем не менее, по примеру стран- 
лидеров в 2014 г. этим законом [ст. 24.2, п. 1,4] была введена ответственность производителей за утилизацчию отходов:

n. 1. Производители, импортеры товаров обязаны обеспечивать утилизаџию отходов от использования этих товаров в соответствии с нормативами утилизации, установленными Правительством Российской Федерации;

n.4. Обеспечение выполнения нормативов утилизации осуществляется непосредственно самими производителем, импортером товаров путем организации собственных объектов инфраструктуры по сбору, обработке, утилизации отходов от использования таких товаров или путем заключения договоров с оператором по обращеению с твердыми коммунальными отходами, региональным оператором, с индивидуальным предпринимателем, юридическим личом, осуществляющими деятельность по сбору, транспортированию, обработке, утилизаџии отходов (за исключением твердых коммунальных отходов).

Впервые этим законом транспортные средства, а именно - колёсная и самоходная техника, каждый прицеп к ним, были выделены в отдельную категорию продукции и на нее введён утилизационный сбор (в 2012 на колёсную, и в 2014 - на самоходную технику), предназначенный для финансирования разработки и создания системы утилизации этого вида продукции. В отличии от России, ориентирующейся в вопросах утилизации техники только на один законодательный акт [3], в технически развитых странах, которые эффективно решают проблему утилизации техники, имеется целый арсенал нормативных документов, детально регламентирующих механизм обращения с ВЭТ. На рисунке 4 приведены основные директивные документы, которые должны выполнять производители техники при обращении с отходами, на рисунке 5 - международная иерархия отходов [7]. 


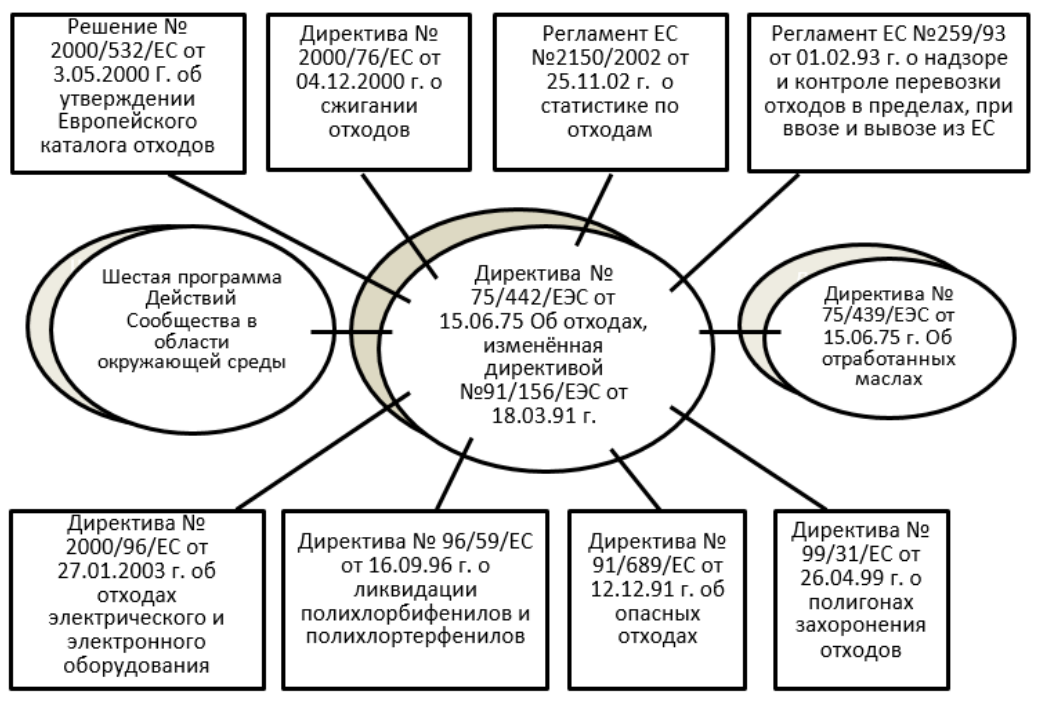

Рисунок 4 - Нормативно-законодательные документы ЕС (ЕЭС) в вопросах обращения с отходами

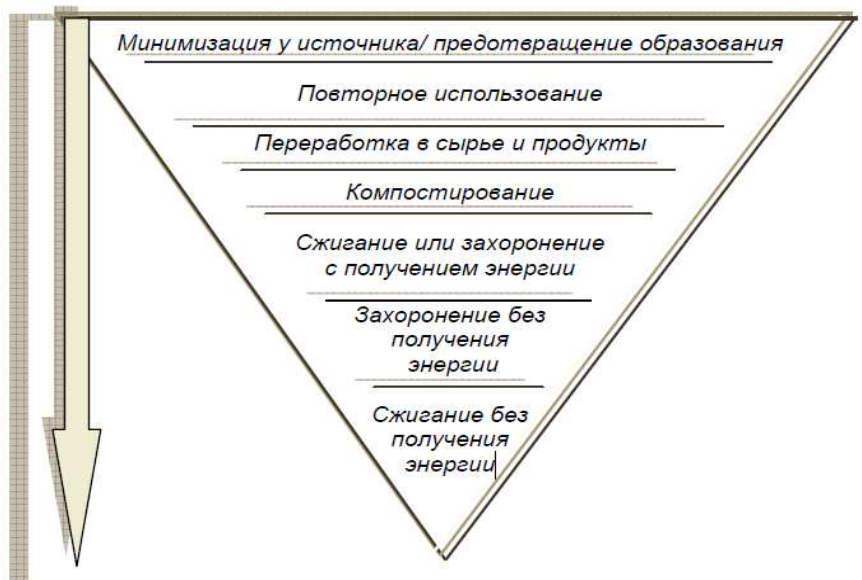

Рисунок 5 - Международная иерархия отходов

В соответствии с этими документами зарубежные производители проводят широкий спектр работ, направленных на предотвращение образования отходов на всех стадиях ЖЦП и снижение негативного воздействия на окружающую среду. С этой целю, они конструируют машины с «учетом экологии» (Директива 2000/53/ЕС), используя методологию полного жизненного цикла продукции. Базовое направление минимизации отходов для производителей транспортных средств сформулировано в п.2 Директивы 2005/64/EC:

«Возможность повторного использования комплектующих деталей, пригодность к переработке для вторичного использования и восстанавливаемость материалов составляют важную часть стратегии Сообщества в организачии сбора, удаления и переработки отходов. Поэтому производители транспортных средств и их поставщики обязаны предусмотреть эти меры на ранних стадиях разработки новых 
транспортных средств с ичелью облегчения утилизации транспортных средств после выработки ими ресурса».

Так, например, в США предприятия-демонтажеры образуют Американскую Ассоциацию Рециклеров (ARA). Другой организацией, связанной с управлением системой авторециклинга является Совет по Автомобильным Исследованиям (USCAR). В рамках USCAR работают две исследовательские группы - Партнерство Рециклинга Транспортных Средств (Vehicle Recycling Partnership, VRP) и Партнерство США по Материалам Автомобиля (USAMP). Партнерства ведут исследования в области проектирования для рециклинга, новых технологий переработки АТО, оптимизации процессов жизненного цикла автомобиля, и пр. В координацию системы вовлечены организации, связанные с переработкой рециклированных материалов [7].

Как показывает мировой и отечественный опыт, производители колёсной, самоходной и прочей техники должны выполнять ряд работ на различных этапах ЖЦП для обеспечения безопасности использования и снижения затрат на утилизацию производимой ими техники (таблица 1).

Отечественные производители техники пока игнорируют требования закона [3], ГОСТов и другой нормативной документации, в том числе по разработке документов по утилизации, в том числе - инструкции по утилизации, которая входит в состав конструкторских документов [8].

С 01.09. 2014 г. вступили в действие новые стандарты: ГОСТ 319682013 и ГОСТ 31969-2013. Основная особенностью этих стандартов является то, что они ориентируют производителей на проведение НИР в области утилизации выпускаемого ими оборудования и на приобретение опыта по отработке технологий утилизации. Это те направления, которые российские производители самоходной техники пока не используют. 
Таблица 4 - Виды работ в плане утилизации, которые должны выполнять производители колёсной и самоходной техники

\begin{tabular}{|c|c|c|c|}
\hline & Этап ЖЦП & Виды работ & Основание \\
\hline 1. & \multirow{5}{*}{ Проектирование } & минимизации образования отходов & директивы ЕС \\
\hline 2. & & обеспечение маркировки деталей & $\begin{array}{l}\text { директива } \\
\text { 2003/138/EC }\end{array}$ \\
\hline 3. & & $\begin{array}{l}\text { снижение применения тяжёлых матери- } \\
\text { алов }\end{array}$ & $\begin{array}{l}\text { директива } \\
\text { 2005/673/ЕС }\end{array}$ \\
\hline 4. & & определение коэффициентов утилизации & $\begin{array}{l}\text { ISO 22628:2002 } \\
\text { ГОСТ 31968-2013 }\end{array}$ \\
\hline 5. & & разработка инструкций по утилизации & ГОСТ 2.601-2013 \\
\hline 6. & Эксплуатация & $\begin{array}{l}\text { формирование сети утилизационных } \\
\text { предприятий }\end{array}$ & закон № 89-Ф3 \\
\hline 7. & \multirow{2}{*}{ Утилизация } & $\begin{array}{l}\text { технологическая поддержка утилизаци- } \\
\text { онных предприятий }\end{array}$ & ГОСТ 2.601-2013 \\
\hline 8. & & $\begin{array}{l}\text { участие в утилизации ВЭТ, контроль над } \\
\text { выполнением нормой утилизации }\end{array}$ & закон № 89-Ф3 \\
\hline
\end{tabular}

Негативным моментом в принципиальном решении проблемы утилизации колёсной, самоходной и прочей техники в России является недостаточное участие государственных структур в разработке эффективной системы ё̈ утилизации. За прошедшую с момента начала накопления средств от утилизационного сбора (2012 г.) пятилетку такого рода работы не поставлены на государственный контроль и не финансируются. Российские производители техники, в отличии от их зарубежных коллег, практически отстранены от участия в создании такой системы, не формируют технологическую документацию на проведение утилизационных работ, не участвуют в создании утилизационных предприятий, поскольку создание таких предприятий требуют дополнительных инвестиций. Владельцы устаревшей техники не заинтересованы в её утилизации, поскольку механизм взаимодействия между участниками системы утилизации пока отсутствует, и у владельцев нет стимула для передачи техники на утилизацию.

В России работы по формированию системы утилизации самоходной техники, в течение последних лет проводятся в Федеральном научном агроинженерном центре ВИМ [7] и колёсной техники в МАДИ [9]. В Федеральном научном агроинженерном центре ВИМ ведутся работы: по фор- 
мированию организационно-технологической структуры системы утилизации сельскохозяйственной техники (далее - Cистема) $[10,11]$; определены инвестиции, требующиеся для её реализации и показатели эффективности при её внедрении [12]; определены границы предельного состояния машины, при достижении которых целесообразно эту технику утилизировать [13], решается ещё ряд вопросов, касающихся решения этой проблемы. Все эти работы направлены на формирование эффективной Cuстемы, учитывающей требования ресурсосбережения и экологии, но до настоящего времени они не востребованы.

Вступление в ВТО обязывает Россию соблюдать международные рекомендации (Директивы) в различных сферах деятельности, в том числе при производстве и утилизации транспортных средств. Необходимость соблюдения этих рекомендаций российскими производителями транспортных средств предопределяется также законом [3], в котором на производителей техники возлагается ответственность за проведение безопасной утилизации ВЭТ. При этом следует учесть, что трудоёмкость, стоимость, эффективность и безопасность проведения утилизационных работ зависит от того, какие технические решения будут заложены в конструкцию машины уже на ранних стадиях её жизненного цикла (см. рис. 3 и табл. 1).

Ещё одним важным фактором, обеспечивающим эффективность проведения утилизации ВЭТ, является разработка её производителями технической документации (подробных инструкций) по проведению утилизации ВЭТ. Это связано с тем, что своевременная организация выполнения законодательных и учет перспективных экологических требований является обязательным условием работы над новыми проектами техники на ранних стадиях ЖЦП. При конструировании рекомендуется стремиться к использованию совместимых с точки зрения повторного использования материалов, входящих в состав машины. Узлы машины должны проектироваться таким образом, чтобы максимально снизить время, требуемое для 
разборки данного узла. Также нужно снижать количество узлов, которые необходимо «извлекать» путем предварительной разборки других узлов, то есть снижать количество уровней разборки. Технология соединения должна выбираться таким образом, чтобы разборка узлов не требовала больших затрат труда и времени, то есть была экономически целесообразной. Особенно это важно в случаях, когда между собой соединяют детали из разных материалов. Такие детали невозможно сортировать без разборки. Для упрощения сортировки компонентов ВЭТ рекомендуется осуществлять маркировку материалов, например, с помощью системы штрихкодирования, используя стандарты SAE J1344 и J2332, германский стандарт VDA 260, международные стандарты ISO 1043 и ISO-11469.В первую очередь это относится к пластмассам и резинам. Все эти мероприятия направлены с одной стороны - на упрощение и снижение стоимости процедуры проведения утилизации ВЭТ, с другой на обеспечение максимально возможного возврата в производство имеющихся в ВЭТ компонентов.

На основе отечественного и зарубежного опыта в ВИМе разработаны рекомендации для заводов-изготовителей сельхозтехники и предприятий инженерной сферы АПК по проведению утилизации этой техники после окончания срока её эксплуатации [14]. В настоящее время лидером по проведению работ, касающихся экологической безопасности и утилепригодности разрабатываемых и производимых автомобилей среди российских производителей техники является ОАО «АВТОВАЗ». Для соответствия автомобилей LADA установленным и перспективным отечественным и международным экологическим законам и нормативам, разрабатываются и включаются в состав проектных документов специальные разделы, которые содержат необходимые требования и целевые параметры по обеспечению экологической безопасности автомобилей семейства. Такие требования распространяются, в том числе, и на заключительную фазу - эффективную и экологически безопасную утилизацию ВЭТ. 
Особое внимание уделяется взаимодействию с предприятиями, проводящими утилизацию устаревшей техники и разработке для этих предприятий системы нормативной документации, охватывающей и регулирующей данную область, в том числе документов, определяющих: порядок обеспечения экологической безопасности автомобилей при разработке проектов в ОАО «АВТОВАЗ»; порядок разработки нормативных документов на материалы в ОАО «АВТОВАЗ»; характер информации, передаваемой ОАО «АВТОВАЗ» сторонним организациям для использования при утилизации автомобилей ВАЗ; порядок работы с материалами при подготовке производства новых и модернизированных автомобилей; требования к маркировке автомобильных компонентов для идентификации применяемых материалов и др.

Выстроенная система информационного взаимодействия с поставщиками материалов и компонентов, содержащая требования и рекомендации по обеспечению экологической безопасности автомобильных компонентов и материалов, доступна для поставщиков (изготовителей, разработчиков, утилизаторов), и размещена на информационном интернет-ресурсе «Технопортал ОАО «АВТОВАЗ», вкладка «Партнеры» (http://tportal.vaz.ru). Данная документация содержит основные правила, требования, указания и рекомендации, способствующие повышению экологической безопасности изделий, сокращению применения вредных веществ в составе компонентов и материалов автомобиля, повышению удобства и технологичности демонтажа узлов, пригодности их к вторичной переработке и утилизации.

Конструкторские, технологические, исследовательские и проектные отделы НТЦ ОАО «АВТОВАЗ» проводят работу по реализации требований по экологической безопасности и утилизации разрабатываемых автомобилей на основании проектной и нормативной документации, а также выпущенных приказов, распоряжений, программ и протоколов решений. 
Для всех моделей автомобилей LADA, проданных и продаваемых в странах EC, разработана и направлена через фирмы-импортеры OAO «АВТОBA3» на предприятия по утилизации специальная документация, соответствующая Директиве 2000/53/EC, в том числе: «Каталог демонтажа компонентов автомобиля для целей утилизации» (рисунок 7), «Руководство по ускоренному осушению и демонтажу узлов и деталей автомобиля». Со стороны официальных дилеров и импортеров ОАО «АВТОВАЗ» в странах ЕС заключены долговременные контракты с ведущими фирмами, занимающимися утилизацией отслуживших автомобилей, на сбор и переработку выведенных из эксплуатации автомобилей LADA.

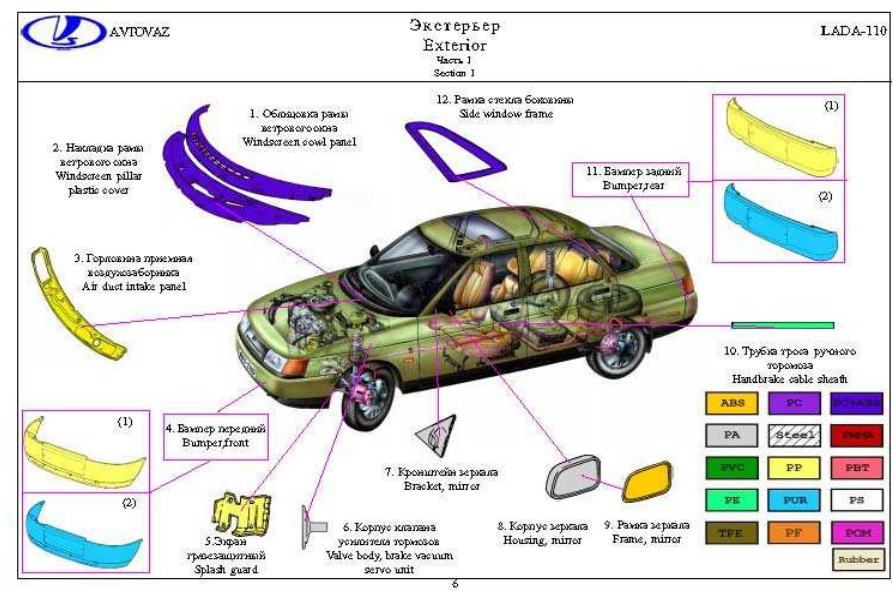

Рисунок 8 - Фрагмент из Каталога демонтажа компонентов автомобиля LADA-110, выполненного в соответствии с Директивой 2000/53/EC (дата выпуска 2002г.)

Однако эти работы проводятся только для экспортных машин. Для машин, проданных в России, эти работы не ведутся. Это говорит о том, что государство пока не требует от производителей выполнения требований закона [3], поскольку само не выполняет статью 24 «Экономическое стимулирование деятельности в области обращения с отходами» этого закона, в соответствии с которой средства от утилизационного (экологического) сбора «в приоритетном порядке предназначаются для выполнения нормативов утилизации отходов от использования товаров, в том числе строительства, реконструкции, технического перевооружения, модернизации производственно-технических комплексов, осущуествляющих обращение с отходами». 
Тем не менее, опыт и наработки ОАО «АВТОВАЗ» по выполнению директив ЕС и требований российской нормативной документации в области утилизации может служить базой для производителей колёсной, самоходной и прочей техники, которые до настоящего момента не включились в решение этой проблемы, а наработки МАДИ и ВИМ - для создания в России отраслевых систем утилизации ВЭТ.

Выводы

1. Отходы производства и потребления в последние десятилетия создали общемировую проблему, которая таит в себе угрозу всему человечеству. Решить эту проблему можно только путём их утилизации и повторного использования компонентов, входящих в состав этих отходов.

2. Наиболее материалоёмкими и экологоопасными являются отходы от выведенной из эксплуатации техники, которая требует утилизации с соблюдением соответствующих требований ресурсосбережения и экологии.

3. В технически развитых странах, которые эффективно решают проблему утилизации техники, имеется целый арсенал нормативных документов, регламентирующих работы производителей техники по повышению утилепригодности выпускаемой ими техники на всех стадиях её (техники) жизненного цикла и механизм обращения с ВЭТ, который предусматривает создание системы утилизации этой техники её производителями, которые необходимо выполнять и российским производителям техники.

4. Россия существенно отстаёт от стран-лидеров в решении проблемы утилизации техники. Её производители в настоящее время пока не включились в процесс утилизации ВЭТ собственного производства, игнорируя требования российского законодательства и нормативные документы. В значительной мере это связано с тем, что создание системы утилиза- 
ции техники пока не поставлено на контроль государства и не финансируется в соответствии с законом [3].

5. В настоящее время лидером среди российских производителей колёсной техники по проведению работ, касающихся экологической безопасности и утилепригодности разрабатываемых и производимых автомобилей является ОАО «АВТОВАЗ». Опыт АВТОВАЗа может служить для интенсификации работ по созданию утилепригодной колёсной и самоходной техники и системы её утилизации.

6. Для создания в России отраслевых систем утилизации самоходной техники различных видов могут быть использованы наработки МАДИ, а также Федерального научного агроинженерного центра ВИМ, в котором сформирована концепция и базовые положения отраслевой системы утилизации сельскохозяйственной техники.

\section{Литература}

1 Мировая экономика: глобальные тенденции за 100 лет / Под ред. И.С. Королева. - М.: Юристь, 2003. - 604 с.

2 С. П. Капица, Феноменологическая теория роста населения Земли, УФН. 1996, - т. 166, № 1, - С. 63-80.

3 Федеральный закон РФ «Об отходах производства и потребления» от 24.06.1998 № 89-Ф3: [принят Гос. Думой 22.05.1998 г.: действующая редакция] //СПС КонсультантПлюс.

4 Модельный закон "Об отходах производства и потребления" (принят постановлением на 29 пленарном заседании Межпарламентской Ассамблеи государств участников СНГ от 31 октября 2007 г. N 29-15). [Электронный ресурс] // КонсультантПлюс.

5 Игнатов, В.И. Техника, как особый вид отходов / В.С.Герасимов Р.Ю.Соловьев, В.И.Игнатов, С.А.Буряков // Сельскохозяйственная техника: обслуживание и ремонт. - 2016. -№ 6. - С. 47 - 54.

6 Профессор Ян-Дирк Хербель. Основные черты системы управления отходами в Германии. 18-19 июня 2007, ИрГТУ. [электронный ресурс]. - 26.06.2016. - режим доступа:

http://www.baikal-

waste.eu/rus/pdf/publikationen/upravlenie_othodami_v_Germanii.pdf

7 Утилизация сельскохозяйственной техники проблемы и решения: науч. издание / С.А. Соловьёв, В.Ф. Федоренко, В.И. Игнатов и др.. - М.: ФГБНУ «Росинформагротех»-172 с. ISBN 978-5-7367-1132-1.

8 Трофименко Ю.В., Воронцов Ю.М., Трофименко К.Ю. Утилизация автомобилей. - М.: ООО «АКПРЕСС», 2011. - 332 с.

9 ГОСТ 2.601-2013 ЕСКД. Эксплуатационные документы.

10 Игнатов, В.И. Организационно-технологический комплекс работ по утилизации сельскохозяйственной техники / В.И. Игнатов // Политематический сетевой элек- 
тронный научный журнал Кубанского государственного аграрного университета (Научный журнал КубГАУ) [Электронный ресурс]. Режим доступа: http://ej.kubagro.ru/2017/04/pdf/63.pdf -. Краснодар: КубГАУ. - 2017. - №04(128). С. $942-954$.

11 Игнатов, В.И. Новая концепция формирования системы утилизации техники / В.И. Игнатов // Политематический сетевой электронный научный журнал Кубанского государственного аграрного университета (Научный журнал КубГАУ) [Электронный pecypc]. Режим доступа: http://ej.kubagro.ru/2016/07/pdf/66.pdf. - Краснодар: КубГАУ. 2016. - № 07(121). - С. 1065-1080.

12 Игнатов, В.И. Эффективность разработки и внедрения системы утилизации техники специализированных производств / Н.В. Артюх, В.С. Герасимов, В.И. Игнатов, А.Ю. Тесовский, Ю.А. Шамарин // Строительные и дорожные машины. -2017. - № 2. C. 44-52.

13 Игнатов, В.И. Теоретическое обоснования границ целесообразности утилизации машины / В.И. Игнатов, Н.С. Еремеев // Политематический сетевой электронный научный журнал Кубанского государственного аграрного университета (Научный журнал КубГАУ) [Электронный доступа: http://ej.kubagro.ru/2016/08/pdf/23.pdf. - Краснодар: КубГАУ. - 2016. № 08(122). - C. 318-337.

14 Игнатов, В.И. Обоснование создания системы «Сельхозрециклинг» с участием заводов-изготовителей и предприятий инженерной сферы АПК: брошюра. / Р.Ю. Соловьёв, В.С. Герасимов; В.И. Игнатов, С.А.Буряков. - М.: ФГБНУ ФНАЦ ВИМ, - 2017. $56 \mathrm{c}$.

15 Р.Л. Петров. Выполнение современных требований по рециклингу и утилизации в конструкции и материалах автомобилей LADA / Журнал Автомобильных Инженеров - 2011№4 (69).

16 Директива 2003/138/ЕС по маркировке пластмассовых и резиновых деталей для целей утилизации.

\section{References}

1. Mirovaya ekonomika: global'nye tendentsii za 100 let (World economy: global tendencies for 100 years), Moscow: Yurist", 2003, 604p.

2. Kapitsa S. P., Fenomenologicheskaya teoriya rosta naseleniya Zemli, UFN, 1996, vol. 166, No 1, pp. 63-80.

3. FZ RF 89-FZ (Federal law of the Russian Federation No 89) «Ob otkhodakh proizvodstva i potrebleniya» ot 24.06.1998, SPS “Konsul'tant".

4. Model'nyi zakon (Model law No 29-15) "Ob otkhodakh proizvodstva i potrebleniya" (prinyat postanovleniem na 29 plenarnom zasedanii Mezhparlamentskoi Assamblei gosudarstv - uchastnikov SNG ot 31 oktyabrya 2007 g. N 29-15), SPS “Konsul'tant”.

5. Ignatov V.I., Gerasimov V.S., Solov'ev R.Yu., Buryakov S.A. Tekhnika, kak osobyi vid otkhodov (Equipment as a special type of waste), Sel'skokhozyaistvennaya tekhnika: obsluzhivanie i remont, 2016, No 6, pp. $47-54$.

6. Yan-Dirk Kherbel' Osnovnye cherty sistemy upravleniya otkhodami v Germanii (Main characteristics of waste management system in Germany) 18-19 June 2007, IrGTU. Available at: waste.eu/rus/pdf/publikationen/upravlenie_othodami_v_Germanii.pdf

7. Solov'ev S.A., Fedorenko V.F., Ignatov V.I. Utilizatsiya sel'skokhozyaistvennoi tekhniki problemy i resheniya (Utilization of agricultural machines problems and solutions), Moscow: FGBNU «Rosinformagrotekh», 172 p. ISBN 978-5-7367-1132-1. 
8. Trofimenko Yu.V., Vorontsov Yu.M., Trofimenko K.Yu. Utilizatsiya avtomobilei (Cars utilization), Moscow, OOO «AKPRESS», 2011. - 332 p.

9. GOST 2.601-2013 ESKD. Ekspluatatsionnye dokumenty.

10. Ignatov V.I. Organizatsionno-tekhnologicheskii kompleks rabot po utilizatsii sel'skokhozyaistvennoi tekhniki (Structural and tecgnological set of works for utilizitaion of agricultural machines), Politematicheskii setevoi elektronnyi nauchnyi zhurnal Kubanskogo gosudarstvennogo agrarnogo universiteta (Nauchnyi zhurnal KubGAU) Available at: http://ej.kubagro.ru/2017/04/pdf/63.pdf . Krasnodar: KubGAU, 2017, No 04(128) pp. 942 954.

11. Ignatov V.I. Novaya kontseptsiya formirovaniya sistemy utilizatsii tekhniki, Politematicheskii setevoi elektronnyi nauchnyi zhurnal Kubanskogo go-sudarstvennogo agrarnogo universiteta (Nauchnyi zhurnal KubGAU) Available at: http://ej.kubagro.ru/2016/07/pdf/66.pdf. Krasnodar: KubGAU, 2016, No 07(121), pp. 10651080 .

12. Ignatov V.I., Artyukh N.V., Gerasimov V.S., Tesovskii A.Yu. Shamarin Yu.A. Effektivnost' razrabotki i vnedreniya sistemy utilizatsii tekhniki spetsializirovannykh proizvodstv, Stroitel'nye i dorozhnye mashiny, 2017, No 2., pp. 44-52.

13. Ignatov V.I., Eremeev N.S. Teoreticheskoe obosnovaniya granits tselesoobraznosti utilizatsii mashiny, Politematicheskii setevoi elektronnyi nauchnyi zhurnal Kubanskogo gosudarstvennogo agrarnogo universiteta (Nauchnyi zhurnal KubGAU) Available at: http://ej.kubagro.ru/2016/08/pdf/23.pdf. Krasnodar: KubGAU, 2016, No 08(122), pp. 318337.

14. Ignatov V.I., Solov'ev R.Yu., Gerasimov V.S., Buryakov S.A.Obosnovanie sozdaniya sistemy «Sel'khozretsikling» s uchastiem zavodov-izgotovitelei i predpriyatii inzhenernoi sfery APK, Moscow: FGBNU FNATs VIM, 2017. - 56 p.

15. Petrov R.L. Vypolnenie sovremennykh trebovanii po retsiklingu i utilizatsii $\mathrm{v}$ konstruktsii i materialakh avtomobilei LADA, Zhurnal Avtomobil'nykh Inzhenerov, 2011, No 4 (69).

16. Direktiva 2003/138/ES po markirovke plastmassovykh i rezinovykh detalei dlya tselei utilizatsii. 